\title{
EFFECTIVITY OF PNEUMATIC RETINOPEXY PROCEDURE IN PRIMARY RHEGMATOGENOUS RETINAL DETACHMENT (RRD)
}

\author{
Soefiandi Soedarman ${ }^{1}$, Soedarman Sjamsoe ${ }^{1}$, Waldensius Girsang ${ }^{1}$, Elvioza ${ }^{1}$, Gitalisa Andayani ${ }^{1}$, Referano \\ Agustiawan $^{1}$ \\ ${ }^{1} J E C$ Eye Hospitals \& Clinics, Indonesia
}

\section{ABSTRACT}

Introduction: To evaluate the effectiveness of pneumatic retinopexy (PR) for repair of primary rhegmatogenous retinal detachment (RRD) with respect to single operation success (SOS) and best corrected visual acuity (BCVA).

Methods: This retrospective review comprised 8 eyes with primary rhegmatogenous retinal detachment with superior break that undergone pneumatic retinopexy as the initial procedure between 2009-2014 at Jakarta Eye Center, Indonesia.

Result: The mean age of subjects was $49 \pm 14.35$ years. Four subjects ( $50 \%)$ had Single operation had only done success after 6 months of observation. The eyes that failed single procedure underwent vitrectomy and silicon oil tamponade. Subjects that only done single procedure had better BCVA (0.01 $\pm 1,3 \log M A R)$ compare to subjects that done secondary procedure $(0.3 \pm 0.42 \log M A R)$ after 6 months of observation.

Conclusion: Pneumatic retinopexy is still an effective procedure for primary rhegmatogenous retinal detachment with superior breaks although in our study the single operation success was $50 \%$.

Keywords: pneumatic retinopexy, rhegmatogenous retinal detachment, retinal break

Cite This Article: SOEDARMAN, soefiandi. EFFECTIVITY OF PNEUMATIC RETINOPEXY PROCEDURE IN PRIMARY RHEGMATOGENOUS RETINAL DETACHMENT (RRD. International Journal of Retina, [S.I.], v. 3, n. 2, sep. 2020. ISSN 2614-8536. Available at: <https://www.ijretina.com/index.php/ijretina/article/view/116

*Correspondence to:

Sandi Soedarman,

JEC Eye Hospitals \& Clinics sandi_soedarman@yahoo.com

\section{INTRODUCTION}

Pneumatic retinopexy (PR) is a minimally invasive surgery in primary rhegmatogenous retinal detachment (RRD). This procedure is first introduced by Domingues, Hilton, and Grizzard in mid-1980.1,2 The procedure is indicated in simple RRD cases with superior tear. A study conducted by Brinton et $\mathrm{al}^{3}$ reported that $40 \%$ of RRD could be treated with PR.

To present date, there is a different opinion regarding the procedure in RRD between European and American vitreoretinal experts. Two large survey in those area resulted in different outcome where majority of American vitreoretinal experts (>50\%) preferred PR as primary procedure in simple RRD while European preferred scleral buckling (SB) as primary procedure in simple RRD. ${ }^{4,5}$

Effectivity of PR are based on 3 principles in RRD treatment such as intraocular gas injection, correct head positioning (half sitting position) for some time to let the injected gas close retinal tear, and retinopexy around the tear with laser or cryo. ${ }^{6}$ Hilton et $\mathrm{al}^{7}$ reported several advantages of this procedure compared to SB or vitrectomy in simple RRD cases with superior tear such as minimal trauma toward eye, no need of post-operative care, and minimal cost estimation 
Jakarta Eye Center (JEC) as one of national ophthalmology hospital became one of hospital that able to provide PR for simple RRD cases. Even though the procedure has been routinely provided, study evaluating effectivity of PR in simple primary RRD with superior tear has not yet done. This study aims to evaluate attachment of retina and change in Best Corrected Visual Acuity (BCVA) 6 month after PR in simple primary RRD. Furthermore, this study also evaluates lens status association with retinal attachment percentage 6 month after PR.

\section{METHODS}

The design of this study is retrospective cohort. The subjects data acquired through medical records. The study was done in Jakarta Eye Center (JEC) Menteng and Kedoya, Jakarta, Indonesia from September-October 2014. The accessible population in this study is primary RRD patients with superior retinal tear underwent $P R$ in January 2009-January 2014 (5 years).

The inclusion criteria are patients with simple primary RRD with superior tear, had pre-operative BCVA and 6 months after PR. Patients suffered from RRD with proliferative vitreoretinopathy (PVR) and involving macula (macula-off), underwent other surgery procedure previously (SB/vitrectomy), had more than 1 quadrant tear, and RRD with other disease such as glaucoma, anterior chamber turbidity, and history of uveitis were excluded. All patients fulfilling criteria recruited as subjects. The variable acquired for this research were age, gender, laterality, pre-operative $B C V A$, pre-operative intraocular pressure (IOP), 1 day post-operative IOP, tear location, lens status, injected gas, post-operative redetachment rate, what procedure if redetachment happened, and procedure complication.

Before PR performed, complete ophthalmology examination such as BCVA examination, biomicroscopic slit-lamp anterior segment examination, and posterior segment examination with indirect ophthalmoscopy with fundus photograph were done. PR procedure then performed with retrobulbar anesthesia. Anterior chamber paracentesis as much as $0.1-0.2 \mathrm{ml}$ were done with $27 \mathrm{G}$ needle. After that, 0.3-0.4 ml perflouropropane (C3F8) or hexafluoride Sulphur (SF6) gas injected at inferotemporal quadrant 3.5-4 mm from limbus. Patients instructed to lay with semi-sitting position for 3 days to let subretinal fluid absorbed. One day after PR, laser retinopexy performed around the tear. Single Operation Success (SOS) defined as successfully re-attached retina after PR procedure only. Retinal detachment defined as a condition where neurosensory layer of retina detached from pigment epithelial layer of retina after the procedure.

Data analysis were done descriptively toward acquired variables using Microsoft Office Excel 2011. Numeric variables presented with mean \pm standard deviation. Categorical variables presented with proportion. Table and graphic of the data were also presented.

\section{RESULTS}

As many as 14 eye subjects were acquired from January 2009 to January 2014 diagnosed with RRD underwent PR. From 14 eyes, 6 subjects were excluded due to previous vitrectomy or SB. As many as 8 subjects were included in this study. Table 1 shown 8 eyes analyzed in this study. The majority of subjects were male.

Table 1. Characteristics of Subjects

\begin{tabular}{lc}
\hline Variable & Frequency (\%) \\
\hline Subjects number & 8 eyes \\
Gender & \\
Male & 5 eyes $(62.5 \%)$ \\
Female & 3 eyes $(37.5 \%)$ \\
Age (Mean \pm SD) & $49 \pm 14.35$ years \\
Pre-operative visual acuity & old \\
(BCVA) (Mean \pm SD) & $0.86 \pm 0.14$ \\
Pre-operative IOP (Mean \pm & $13.63 \pm 1.85$ \\
SD) & mmHg \\
Lens status & \\
Phakia & 6 eyes $(75 \%)$ \\
Pseudophakia & 2 eyes $(25 \%)$ \\
Tear location & \\
Superotemporal & 6 eyes $(75 \%)$ \\
Superonasal & 2 eyes $(25 \%)$ \\
Gas injected & \\
C3F8 & 7 eyes $(87.5 \%)$ \\
SF6 & 1 eye (12.5\%) \\
\hline
\end{tabular}

SD : standard deviation; BCVA: best-corrected visual acuity; IOP: intraocular pressure 
Average age of the subjects were 49 years old. Average pre-operative visual acuity and IOP were 0.86 and 13.63 $\mathrm{mmHg}$. Majority of patients had phakia (75\%) and using C3F8 gas (87.5\%).

Table 2 shown that there were 4 eyes experienced redetachment from total of 8 eyes underwent PR. All patients with redetachment were performed Vitrectomy + SB. In 6 month post-operative period, the BCVA of subjects without redetachment were better than subjects with redetachment underwent vitrectomy + SB (0.98: 0.5). There was no increment of IOP in all subjects 1 day after PR with average of IOP $12.25 \mathrm{mmHg}$.

Table 2. SOS, redetachment, 1-day postoperative IOP, \& 6 month post-operative BCVA

\begin{tabular}{|c|c|}
\hline Variables & Frequency (\%) \\
\hline SOS & 4 eyes $(50 \%)$ \\
\hline Redetachment & 4 eyes $(50 \%)$ \\
\hline Phakia & 3 eyes $(37.5 \%)$ \\
\hline Pseudofakia & 1 eye (12.5\%) \\
\hline 6-month post-operative & $0.74 \pm 0.36$ \\
\hline BCVA & $0.98 \pm 0.05$ \\
\hline PR & $0.5 \pm 0.38$ \\
\hline$P R+V x+S O$ & \\
\hline $\begin{array}{l}\text { 1-day post-operative IOP } \\
(\text { Mean } \pm \text { SD) }\end{array}$ & $\begin{array}{c}12.25 \pm 2.55 \\
\mathrm{mmHg}\end{array}$ \\
\hline \multicolumn{2}{|c|}{$\begin{array}{l}\text { SD : standard deviation; SOS: single operation } \\
\text { success; BCVA: best corrected visual acuity; PR: } \\
\text { pneumatic retinopaxy; Vx: vitrectomy; SO: silicone } \\
\text { oil; IOP: Intraocular pressure. }\end{array}$} \\
\hline \multicolumn{2}{|c|}{$\begin{array}{l}\text { In Table 3, from } 4 \text { eyes suffering from redetachment, } 3 \\
\text { were caused by unidentified or new tear and } 1 \text { eye } \\
\text { caused by inadequate positioning after PR. All subjects } \\
\text { with redetachment were identified by operator at } 7 \text { days } \\
\text { after PR. }\end{array}$} \\
\hline \multicolumn{2}{|c|}{ Tabel 3. Redetachment etiology } \\
\hline Etiology & Frequency (\%) \\
\hline Unidentified or new tear & 3 eyes $(75 \%)$ \\
\hline $\begin{array}{l}\text { Inadequate positioning after } \\
\text { PR }\end{array}$ & 1 eye $(25 \%)$ \\
\hline
\end{tabular}

PR: pneumatic retinopexy.

\section{DISCUSSION}

To this date, PR procedure reported to be effective to treat simple primary RRD with superior tear. In this study, the SOS were achieved in $50 \%$ patients at 6 -month follow-up. A literature review by Hilton et al ${ }^{8}$ reported in 1274 patients from 26 studies underwent PR in 1986 1989 , SOS percentage were $53-100 \%$ with average $80 \%$. Freyler et $\mathrm{al}^{9}$ reported from $89 \mathrm{RD}$ cases underwent $\mathrm{PR}$, SOS achieved in $60.6 \%$ at 5 -years follow-up. Ellakwa ${ }^{10}$ also achieved the same results form 40 cases of RD underwent PR. Another study from Lisle et al ${ }^{11}$ reported rom 36 RD cases, SOS achieved in $83 \%$ subjects at 6 month follow-up.

One of the success indicator in PR is visual acuity (BCVA). In this study, there were increment of BCVA in patients without retinal redetachment. Otherwise, in patients with retinal redetachment with additional procedure such as vitrectomy and SB, reduction of visual acuity 6 -month after procedure could be seen. This result is similar to Ellakwa ${ }^{10}$ study that shown increased visual acuity in subjects with SOS achieved through PR and decreased visual acuity in subjects underwent $P R$ with additional procedure such as vitrectomy and SB after 3 years of observation.

Author concluded that decreased BCVA in cases with $\mathrm{PR}+$ vitrectomy + SB could be caused by macula-off when redetachment happened before vitrectomy + SB. A study conducted by Chen et a ${ }^{12}$ reported that patients underwent PR with macula on had increased visual acuity on $71 \%$ subjects while only $48 \%$ patients with macula-off had increased BCVA.

Pre-operative lens status reported to play a role in PR success. Phakia lens had higher percentage of SOS compared to pseudophakia. Ellakwa ${ }^{10}$ in his study reported that $96.2 \%$ patients without redetachment had phakia lens pre-operatively. Another study by Tornambe $^{13}$ shown a similar result where in subjects without retinal redeetachment after PR, $97 \%$ had phakia lens. Chan et al ${ }^{6}$ stated that there were many tears in peripheral retina unidentified by operator before $P R$ procedure in pseudophakia eyes. It is believed that peripheral vitreoretinal traction is easier to be happened in pseudophakia eyes. Contrast to those studies, in this study $75 \%$ subjects with redetachment had phakic lens status. 
Author concluded that the difference between this study and other studies caused by inadequate sample size.

To the present date, FDA approves SF6 and C3F8 gases to perform retinopexy. In this study 7 (87.5\%) subjects using C3F8. The advantage of the usage of this gas is longer average duration in vitreous chamber for around 38 days compared to SF6 for only 12 days. ${ }^{6}$

In this study, redetachment happened in 1 week after PR. This is in accordance to study by Ellakwa ${ }^{10}$ that reported redetachment incident is highest in 3 months after PR. Freyler et al ${ }^{9}$ also reported from 11 patients with redetachment, 6 were happened 1 month after PR. Tornambe ${ }^{13}$ shown a contrasted result where only $1 \%$ of redetachment cases happened 6 months after PR.

In this study, redetachment mainly caused by new or unidentified tear. Similar with study by Grizzed et al ${ }^{14}$ reported that PR failure caused by unidentified tear $14.9 \%$, re-opened tear $11.2 \%$, and $4.6 \%$ caused by unclosed tear. In this research 1 male patients suffered redetachment caused by inadequate head positioning. Kulkarni et al $^{15}$ shown that male subjects had redetachment caused by inadequate positioning after PR higher than female (32\% : 15.3\%).

One complication of PR procedure is increased IOP 1 day after operation. As many as 8 (20\%) patients had increased IOP 1 day after PR in Ellakwa ${ }^{10}$ study. In this study, there were no patient experienced increased IOP 1 day after PR (mean post-operative IOP $12.25 \mathrm{mmHg}$ ). There were limitations in this study such as retrospective methods of the study using medical records and little sample size.

\section{CONCLUSION}

This study shown that PR is still effective in treating simple primary RRD with superior tear. Although the SOS only $50 \%$ but retinal attachment rate in this study is 100\%. In SOS achieved with PR the increased BCVA 6 month after operation could be seen. Pre-operative lens status didn't predict PR success in this study. Therefore, PR still could be alternative procedure in treating simple primary RRD with superior tear.

\section{REFERENCES}

1. Hilton GF, Grizzard WS. Pneumatic retinopexy. A twostep out-patient operation without conjunctival incision. Ophthalmology 1986; 95(5): 626-41.

2. Dominguez DA. Cirugia precoz y ambulatoria del desprendimiento de retina. Arch Soc Esp Oftalmol 1985; 48: 47-54.

3. Brinton DA, Hilton GF. Pneumatic retinopexy and alternative retinal detachment technique. In: Ryan $\mathrm{SJ}_{\text {, }}$ Wilkinson $C P$, editors. Retina Vol.3, $3^{\text {rd }}$ ed. St Louis, MO: Mosby Inc; 2001: 2047-62.

4. Hoerauf $H$, Heimann $H$, Hansen L, Laqua $H$. Scleral buckle surgery and pneumatic retinopexy. Techniques, indications and results. Ophthalmology 2008; 105(1): 7-18.

5. Benson WE, Chan $P$, Sharma $S$, Snyder WB, Bloome MA, Birch DG. Current popularity of pneumatic retinopexy. Retina 1999; 19(3): 238-41.

6. Chan CK, Lin SG, Nuthi AS, Salib DM. Pneumatic retinopexy for the repair of retinal detachments: a comphrehensive review (1986-2007). Surv Ophthalmol 2008; 53(5): 443-78.

7. Hilton GF, Das T, Majji AB, Jalali S. Pneumatic retinopexy principles and practice. Indian $J$ Ophthalmol 1996; 44(3), 131-43.

8. Hilton GF, Tornambe PE: The Retinal Detachment Study Group: Pneumatic retinopexy. An analysis of intraoperative and postoperative complications. Retina 1991; 11: 285-94.

9. Freyler R, Radax U. Pneumatic retinopexy- a study of 7 years experience. Klin Monatsbl Augenheikd 1993; 202(3): 212-7.

10. Ellakwa AF. Long-term results of pneumatic retinopexy. Clin Ophthalmol 2012; 6: 55-9.

11.Lisle C, Mortensen KK, Sjolie Ak. Pneumatic retinopexy. A long-term follow-up study. Acta Ophthalmol Scand 1998; 76(4): 486-90.

12. Chen JC, Robertson JE, Coonan P, et al: Results and complications of pneumatic retinopexy. Ophthalmology 1988; 95: 601-8.

13. Tornambe PE. Pneumatic retinopexy: the evolution of case selection and surgical technique. A twelve-year study of 3012 eyes. Trans Am Ophthalmol Soc 1997; 95: 551-78.

14. Grizzard WS, Hilton GF, Hammer ME, et al: Pneumatic retinopexy failures: cause, prevention, timing, and management. Ophthalmol 1995; 102: 929-36.

15. Kulkarni KM, Roth DB, Prenner JL: Current visual and anatomic outcomes of pneumatic retinopexy. Retina 2007; 27: 1065-70. 